\title{
Evaluation of Environmental Pollution Caused by Heavy Metal Elements in Natural Ground
}

\author{
Takehiro OHTA, Dr. Sci. \\ Senior Researcher, \\ Laboratory Head, \\ Hideaki ENOMOTO, Dr. Eng. \\ Former Senior Researcher, \\ Laboratory Head, \\ Geology Laboratory, Disaster Prevention Technology Division \\ Takehi KAWAGOE \\ Senior Researcher, \\ Atsushi HASEGAWA \\ Geology Laboratory, Disaster Prevention Technology Division
}

\begin{abstract}
The pollution of ground water caused by the inflow of drainage water from mudstone excavation sites is a serious issue. It has been recognized that the problem results from the discharge of sulfate generated by the decomposition of pyrite contained in the mudstone. Urban natural ground commonly contains mud sediments, and when the underground environment is altered by underground openings, pollution by acid water originating from these mud sediments may occur. The prediction of pollution is therefore important in constructing underground openings. We used numerical simulation to attempt prediction of the spatial extent of pollution caused by the drainage of acid water with heavy metals from mud sediment.
\end{abstract}

Keywords: natural ground, mud sediments, pyrite, heavy metals, discharge

\section{Introduction}

Marine sediments are distributed in the ground under large cities such as Tokyo and Osaka in Japan. These sediments mainly consist of sand and mud, and marine mud sediments commonly contain pyrite $\left(\mathrm{FeS}_{2}\right)$ (Fig. 1). If pyrite comes into contact with groundwater in an oxidized environment, the groundwater becomes acidic due to the sulfate $\left(\mathrm{SO}_{4}{ }^{2-}\right)$ generated by the decomposition of the pyrite [1]. The reactions are shown by the following equations:

$$
\begin{aligned}
& \mathrm{FeS}_{2}+7 / 2 \mathrm{O}_{2}+\mathrm{H}_{2} \mathrm{O} \rightarrow \mathrm{Fe}^{2+}+2 \mathrm{SO}_{4}{ }^{2-}+2 \mathrm{H}^{+} \\
& \mathrm{Fe}^{2+}+1 / 4 \mathrm{O}_{2}+\mathrm{H}^{+} \rightarrow \mathrm{Fe}^{3+}+1 / 2 \mathrm{H}_{2} \mathrm{O} \\
& \mathrm{Fe}^{3+}+3 \mathrm{H}_{2} \mathrm{O}=\mathrm{Fe}(\mathrm{OH})_{3}+3 \mathrm{H}^{+} \\
& \mathrm{FeS}_{2}+14 \mathrm{Fe}^{3+}+8 \mathrm{H}_{2} \mathrm{O} \rightarrow 15 \mathrm{Fe}^{2+}+2 \mathrm{SO}_{4}{ }^{2-}+16 \mathrm{H}^{+}
\end{aligned}
$$

Around cities where marine mud sediments are distributed, there are serious issues with the corrosion of lifeline pipes [2] and the pollution of groundwater because of acid water drainage caused by pyrite decomposition.

In the major Japanese cities mentioned above, infrastructure elements will be developed deep underground. When deep subterranean openings will be excavated, the pyrite in the ground will decompose because of oxidation in the peripheral environment. This gives rise to the risk of pollution in groundwater and the corrosion of structural materials if the infrastructure will be built deep underground. Evaluating and predicting the possibility of sulfate and other toxic substance drainage from mud sediments is therefore an important theme of environmental geology.

In this paper, we report the results of leaching tests on mud sediments and the results from numerical simulation of these tests. We also cover the results of attempts to predict the spatial extent of pollution caused by the

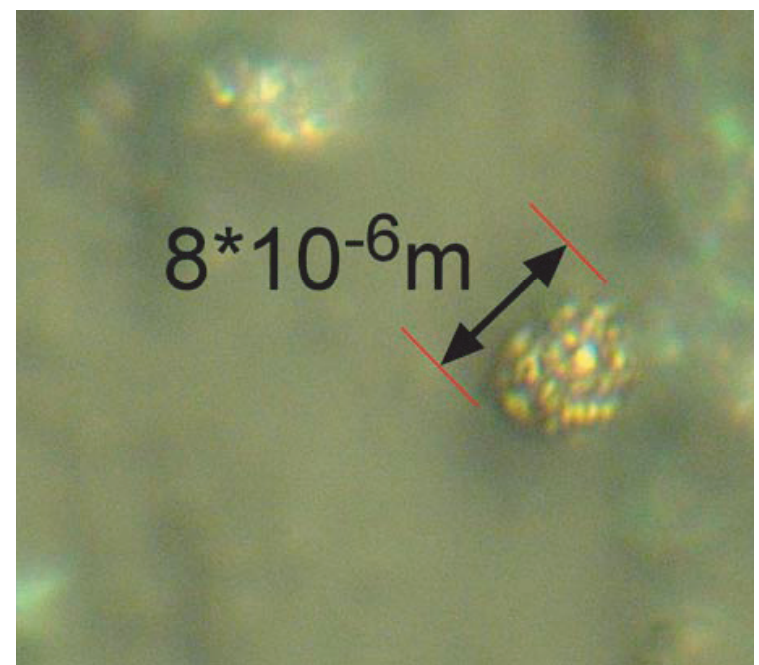

Fig. 1 Digital microscope photograph of pyrite in marine mud sediments

drainage of acid water with heavy metals from mud sediments using numerical simulation that combines advection/diffusion and geochemical models.

\section{Acid water drainage with heavy metals from mud sediments}

Mud sediment samples obtained from several areas were examined through two types of leaching test to clarify the decomposition of minerals in sediments and the drainage phenomenon of acid water with heavy metals. The water quality changes in the leachate of these 
tests were simulated by numerical analysis based on thermo-dynamics and kinetics. In this chapter, we show the results of these tests and simulation, and attempt to construct water-rock reaction models in mud sediment.

\subsection{Batch leaching test}

Mud sediment samples were examined through a batch leaching test to ascertain the sulfate and metal ion drainage characteristics in a state of equilibrium. The mud sediment samples tested were drilling core specimens from the Sagami Group in Tokyo, hand specimens from the Osaka Group in Osaka, hand specimens from the Kazusa Group in Tokyo and Chiba, and core samples from the Yakumo Formation in southwestern Hokkaido.

The test procedure is as follows:

1) The samples are dried and crushed to a grain size of less than $10 \mathrm{~mm}$.

2) Crushed sample portions of $100 \mathrm{~g}$ are mixed with $500 \mathrm{ml}$ of distilled water, and the mixtures are agitated for three minutes.

3) The $\mathrm{pH}$ and electrical conductivity of the leachates are measured after 1 hour, 24 hours, 7 days, 28 days and 56 days.

4) The concentrations of metal elements $(\mathrm{Cu}, \mathrm{Pb}, \mathrm{Zn}$, $\mathrm{Fe}, \mathrm{As}, \mathrm{Cd}, \mathrm{Cr}, \mathrm{Mn}, \mathrm{Se})$ and cations $\left(\mathrm{Na}^{+}, \mathrm{K}^{+}, \mathrm{Ca}^{2+}\right.$, $\left.\mathrm{Mg}^{2+}\right)$ in the leachates after 56 days are determined using ICP emission spectrometry. The sulfate and chlorine ion concentrations in the leachates are determined by the ion chromatography, and the bicarbonate ion content is measured by the sulfate titration method.

\subsubsection{Changes over time in the $\mathrm{pH}$ and electrical conductivity of leachates}

Six samples from the Osaka Group, one from the Kazusa Group in Tokyo and one from the Yakumo Formation became acidic leachates in the batch leaching test (Fig. 2). The $\mathrm{pH}$ of these leachates immediately decreased in the early stages of the test, and became constant after 28 days. The trend of change in the electric conductivities of these leachates was the opposite of the trend for $\mathrm{pH}$; the values increased in the early stages of the test, and became constant after 28 days (Fig. 2).

The leachates of the other samples showed no remarkable change in $\mathrm{pH}$, and indicated a move from neutral to slightly alkaline (Fig. 2). The electric conductivities of these leachates increased with time in the tests.

\subsubsection{Concentrations of ions and metal elements}

Figure 3 shows the concentrations of representative ions, while the concentrations of representative metal elements are illustrated in Fig. 4. Sulfate concentration increases in line with the decreasing $\mathrm{pH}$ of the leachates (Fig. 3). The trend of calcium ion $\left(\mathrm{Ca}^{2+}\right)$ concentration against $\mathrm{pH}$ agrees with the solubility curve of calcium carbonate, i.e., the concentration increases as $\mathrm{pH}$ decreases (Fig. 3). This result suggests that the concentration of calcium ions is controlled by the decomposition of
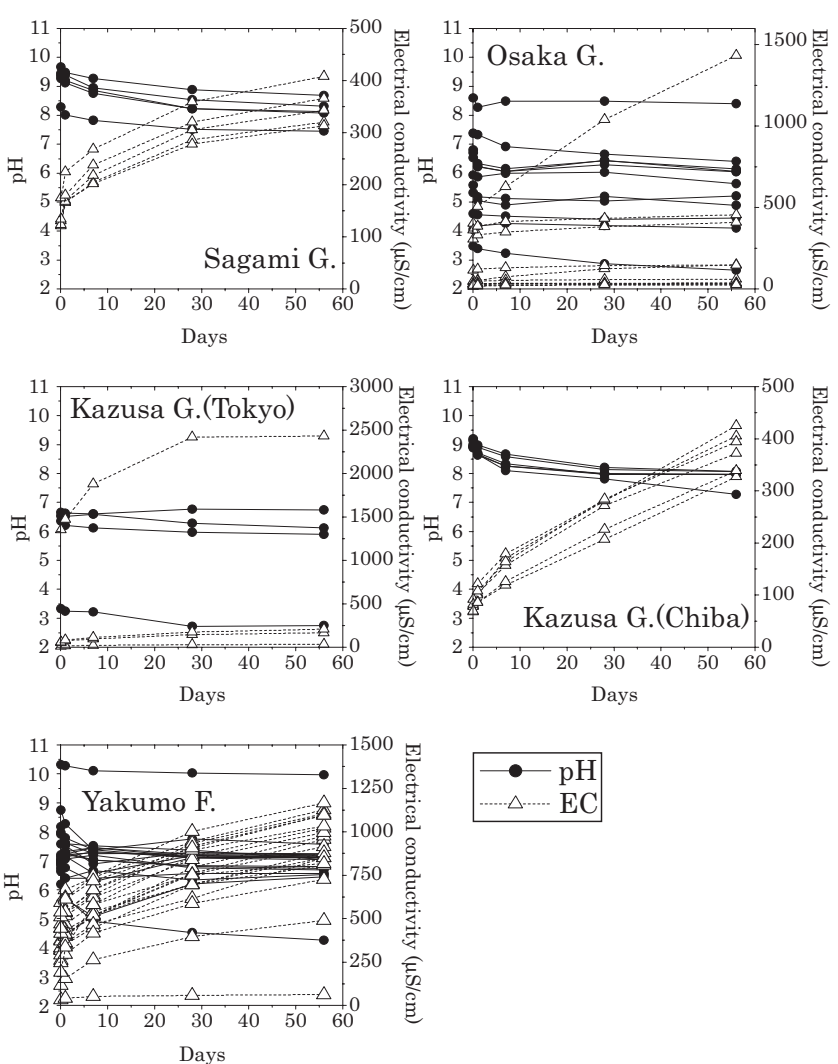

Fig. $2 \mathrm{pH}$ and electrical conductivity of the leachates in the batch leaching test

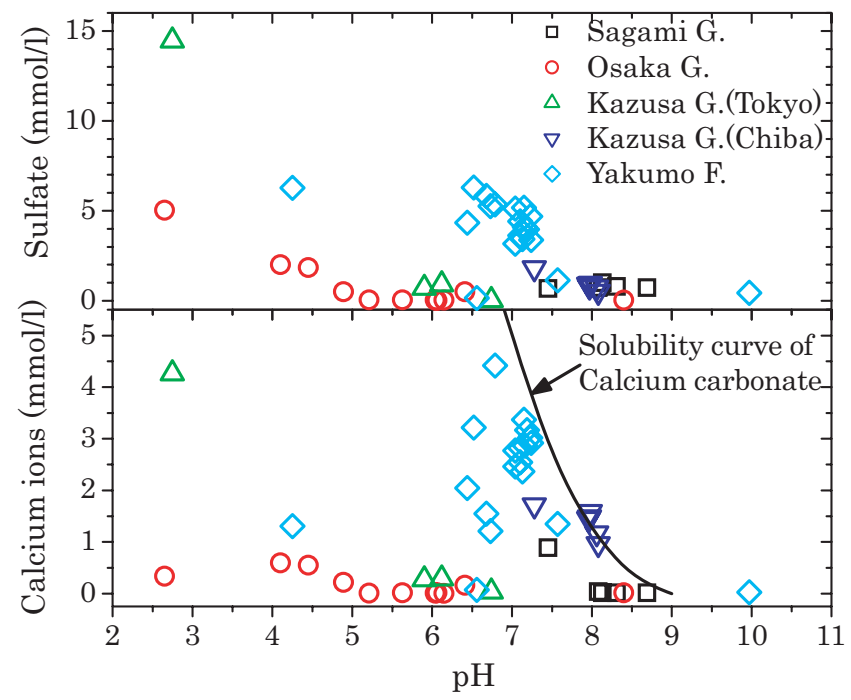

Fig. 3 Concentration of representative ions in the leachates of the batch leaching test

calcite $\left(\mathrm{CaCO}_{3}\right)$. Calcium ion concentration is closely related to sulfate concentration.

The iron in slightly alkaline and alkaline leachates demonstrates low concentration values. The trend of iron concentration against $\mathrm{pH}$ agrees with the solubility curve of ferric hydroxide $\left(\mathrm{Fe}(\mathrm{OH})_{3}\right)$ (Fig. 4). The lead content in the leachates is within $0.0003 \mathrm{mmol} / \mathrm{l}$, and lead concentration increases as $\mathrm{pH}$ decreases. 


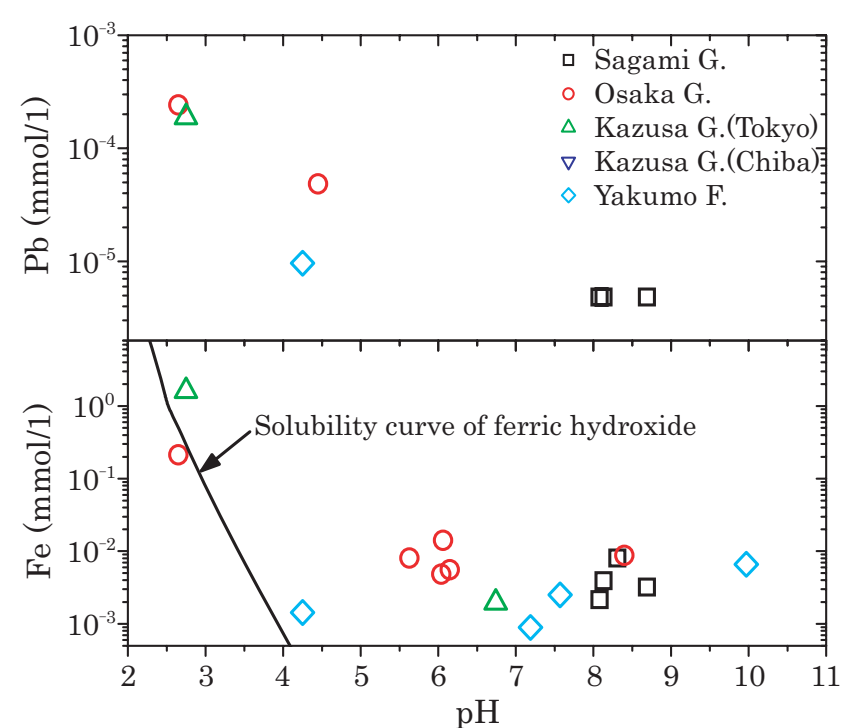

Fig. 4 Concentration of representative metal elements in the leachates of the batch leaching test

\subsubsection{Water and mud sediment reaction mechanism in a state of equilibrium}

As shown in Fig. 2, the leachates in the batch leaching test appear to be in equilibrium with mud sediments after 56 days. Here, we therefore discuss the water and mud sediment reaction mechanism in a state of equilibrium from the water qualities of the leachates after 56 days.

Sulfate is the richest ion in the leachates of the leaching test. As sulfate discharge is caused by the dissolution of sulfide minerals such as pyrite, we can estimate pyrite decomposition as shown in (1). Heavy metal elements such as lead are commonly contained in pyrite as minor elements, and are therefore discharged according to the reaction shown in (1).

The results in Fig. 3 indicate that calcium ion discharge is controlled by calcite solubility. In addition, calcium ion $\left(\mathrm{Ca}^{2+}\right)$ concentration relates to sulfate concentration, and the concentrations of these ions are lower than the gypsum $\left(\mathrm{CaSO}_{4} \cdot 2 \mathrm{H}_{2} \mathrm{O}\right)$ solubility. These facts suggest that the calcium ion and sulfate concentrations are influenced by calcite decomposition (5) and gypsum decomposition and/or precipitation (6).

$$
\begin{aligned}
& \mathrm{CaCO}_{3}+\mathrm{H}^{+} \rightarrow \mathrm{Ca}^{2+}+\mathrm{HCO}_{3}^{-} \\
& \mathrm{Ca}^{2+}+\mathrm{SO}_{4}{ }^{2-}+2 \mathrm{H}_{2} \mathrm{O}=\mathrm{CaSO}_{4} \cdot 2 \mathrm{H}_{2} \mathrm{O}
\end{aligned}
$$

However, not all mud sediments contain calcite. It is probable that anorthite $\left(\mathrm{CaAl}_{2} \mathrm{Si}_{2} \mathrm{O}_{8}\right)$-rich plagioclase is contained in mud sediments as a common calcium-bearing mineral. Anorthite changes to kaolinite $\left(\mathrm{Al}_{2} \mathrm{Si}_{2} \mathrm{O}_{5}(\mathrm{OH})_{4}\right)$ with calcium ion discharge during weathering, as shown in (7).

$$
\mathrm{CaAl}_{2} \mathrm{Si}_{2} \mathrm{O}_{8}+2 \mathrm{H}^{+}+\mathrm{H}_{2} \mathrm{O} \rightarrow \mathrm{Ca}^{2+}+\mathrm{Al}_{2} \mathrm{Si}_{2} \mathrm{O}_{5}(\mathrm{OH})_{4} \text { (7) }
$$

This anorthite reaction appears to influence the water quality of leachate. As both (5) and (7) indicate that the protons in leachate are used in the reactions, these reactions neutralize the leachate that becomes acidic due to pyrite decomposition

As shown in Fig. 4, the iron concentration is very low in slightly-alkaline and alkaline leachates, and increases in line with decreasing $\mathrm{pH}$. Since this trend agrees with ferric hydroxide solubility, precipitation of ferric hydroxide is found in leachate that is more alkaline than the solubility curve shown as (8).

$$
\mathrm{Fe}^{3+}+3 \mathrm{OH}^{-}=\mathrm{Fe}(\mathrm{OH})_{3}
$$

The water quality of leachate is influenced by the reaction shown in (8).

\subsection{Column leaching test}

Mud sediments distributed underground will react with groundwater that flows in the ground. We must therefore consider the flow rate of groundwater in order to understand the reaction mechanism of water and mud in the ground. Mud sediment samples were examined in a column leaching test to ascertain the sulfate and metal ion drainage characteristics in a kinetic state. The tested mud sediment samples were two drilling core specimens from the Yakumo Formation.

The procedure of this test is as follows:

1) The samples are crushed in the same way as for the batch leaching test.

2) Columns of $55 \mathrm{~mm}$ in diameter and $300 \mathrm{~mm}$ in length are filled with the crushed samples.

3) Distilled water flows from the bottom to the top of the columns over a 56-day period under the influence of a micro-pump. Three flow rates of $1 \times 10^{-5}$, $1 \times 10^{-4}$ and $1 \times 10^{-3} \mathrm{~cm} / \mathrm{s}$ are set.

4) The $\mathrm{pH}$, electrical conductivity and concentrations of the metal elements and ions in the leachate that flows out from the columns are measured when the accumulated flow volumes become $500 \mathrm{ml}, 1,000$ $\mathrm{ml}, 2,000 \mathrm{ml}$ and $3,000 \mathrm{ml}$.

\subsubsection{Changes over time in the $\mathrm{pH}$ and electrical conductivity of leachate}

The $\mathrm{pH}$ of leachate increases in line with increments in the accumulated flow volume (Fig. 5). The degree of $\mathrm{pH}$ increase responds to the flow rate, and becomes large as the flow rate becomes slow. The electrical conductivity of leachate decreases rapidly with increments in the accumulated flow volume (Fig. 5). The rate of decrease in electrical conductivity is constant regardless of the flow rate.

\subsubsection{Changes over time in the concentration of ions and metals in leachate}

Figure 6 illustrates changes in representative ion concentrations in leachate. Sulfate and calcium ion concentrations decrease rapidly as the accumulated flow volume increases, and the rates of decrease do not change with the flow rate. The concentration of metal elements in leachate decrease remarkably in line with increments in the accumulated flow volume (Fig. 7). The ratio of decrease in metal elements is not influenced by the flow rate (Fig. 7). These characteristics of metal concentra- 

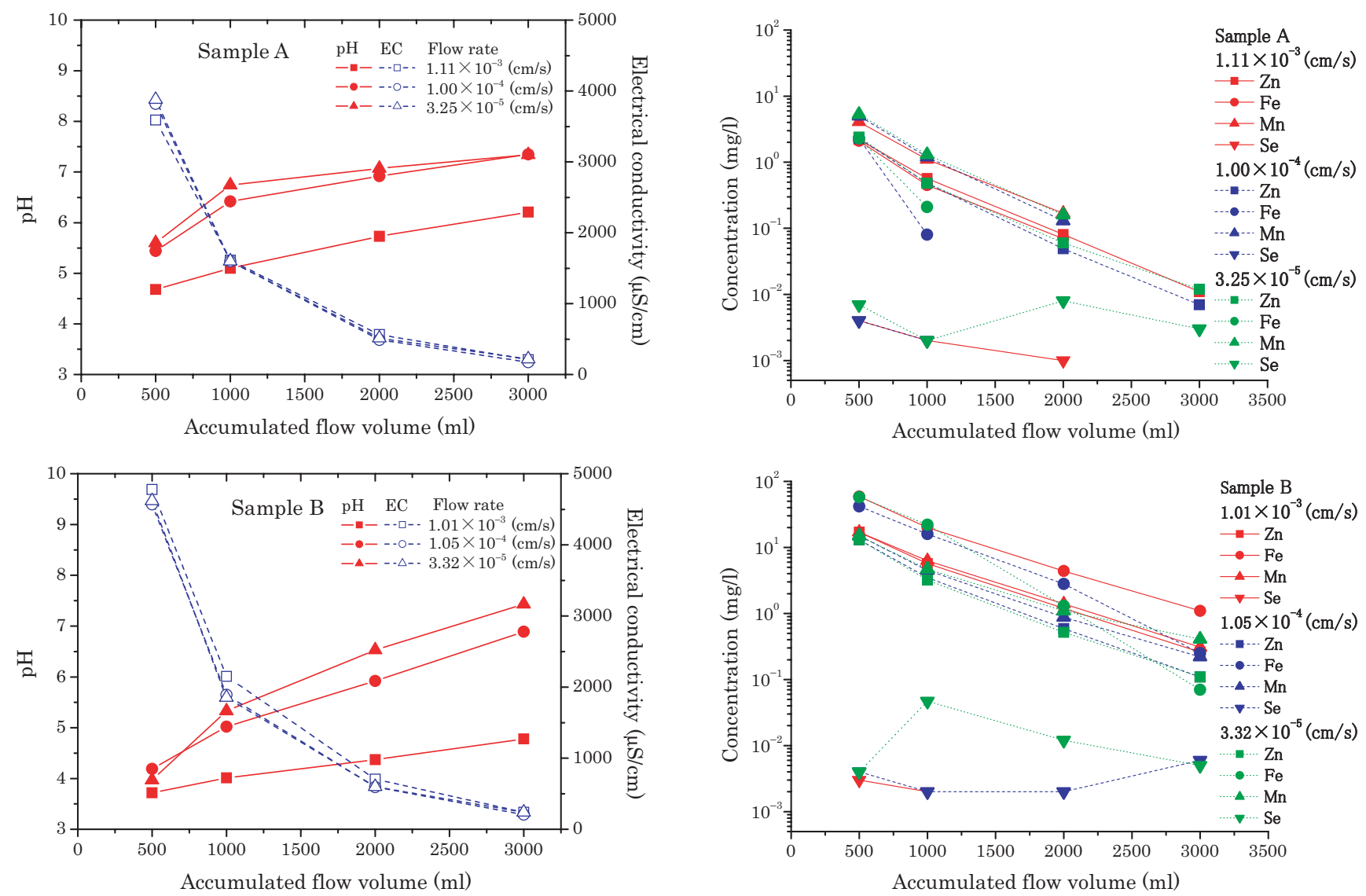

Fig. 5 Changes in $\mathrm{pH}$ and electrical conductivity in leachate against accumulated flow volume

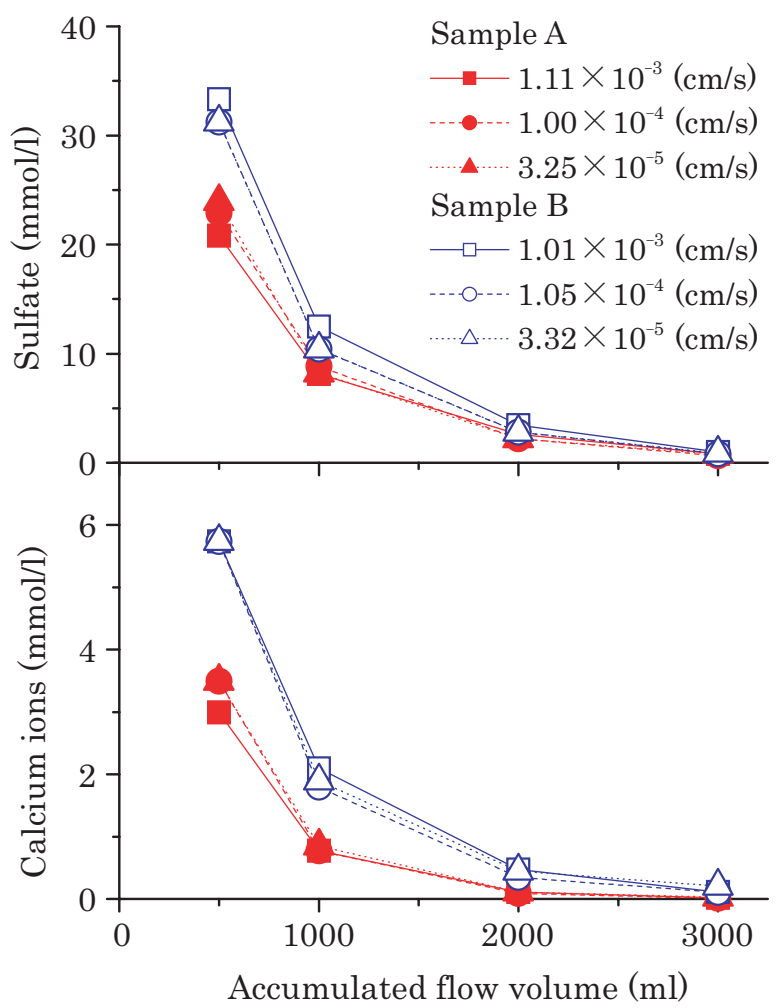

Fig. 6 Changes in representative ion concentrations in leachate against the accumulated flow volume

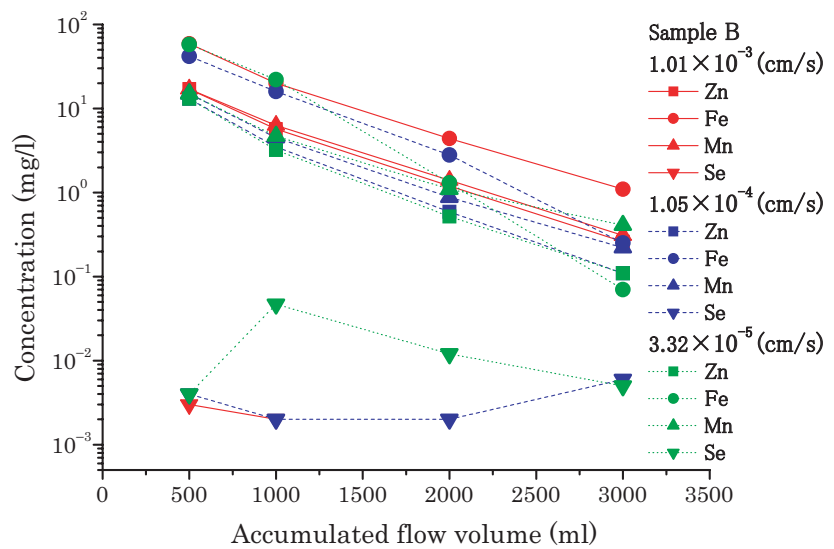

Fig. 7 Change of metal concentrations in leachate against the accumulated flow volume

tion change are the same as the trend of electrical conductivity changes in leachate.

\subsection{Simulation of leaching test using thermo-dynamic analysis}

As outlined above, we estimated the water and mud sediment reaction mechanism in a state of equilibrium based on the results of the batch leaching test. Since the reaction is controlled by thermo-dynamic reaction theory, the estimated mechanism in a state of equilibrium was verified by numerical analysis based on thermo-dynamics, and the results of the column leaching test were simulated using this analysis method. We calculated the reaction using PHREEQC, a well-known geochemical code from the United States Geological Survey [3].

\subsubsection{Verification of the reaction mechanism estimated from the batch leaching test}

The $\mathrm{pH}$ and electrical conductivity of leachate in the batch leaching test changes over time as shown in Fig. 2. This suggests that the water and mud sediment reaction progresses in a kinetic state until the leachate equilibrates to the mud sediment in the test. The change in water quality of the leachate in the test can therefore be simulated in a kinetic state using PHREEQC. We adopted (1) to (8) as the reaction mechanism model. The amount of pyrite is assumed from the sulfur content in the sample, 
while the amounts of calcite and plagioclase are estimated from its $\mathrm{CaO}$ content.

The simulation results are shown in Fig. 8 with the results of the leaching test. The values and trend of change for the calculated $\mathrm{pH}$ are almost the same as those of the $\mathrm{pH}$ measured from the leachate in the leaching test (Fig. 8a). The calculated ion concentrations correspond with the measured electrical conductivity as shown in Fig. 8b, and increase over time in the same way as the measured electrical conductivity. The calculated concentrations of calcium ions, sulfate and bi-carbonate ions after 56 days are similar to the concentrations measured in the leaching test. The results of this calculation indicate that numerical analysis using PHREEQC can simulate watermud sediment reactions, and that the assumed reaction models display some degree of accuracy.
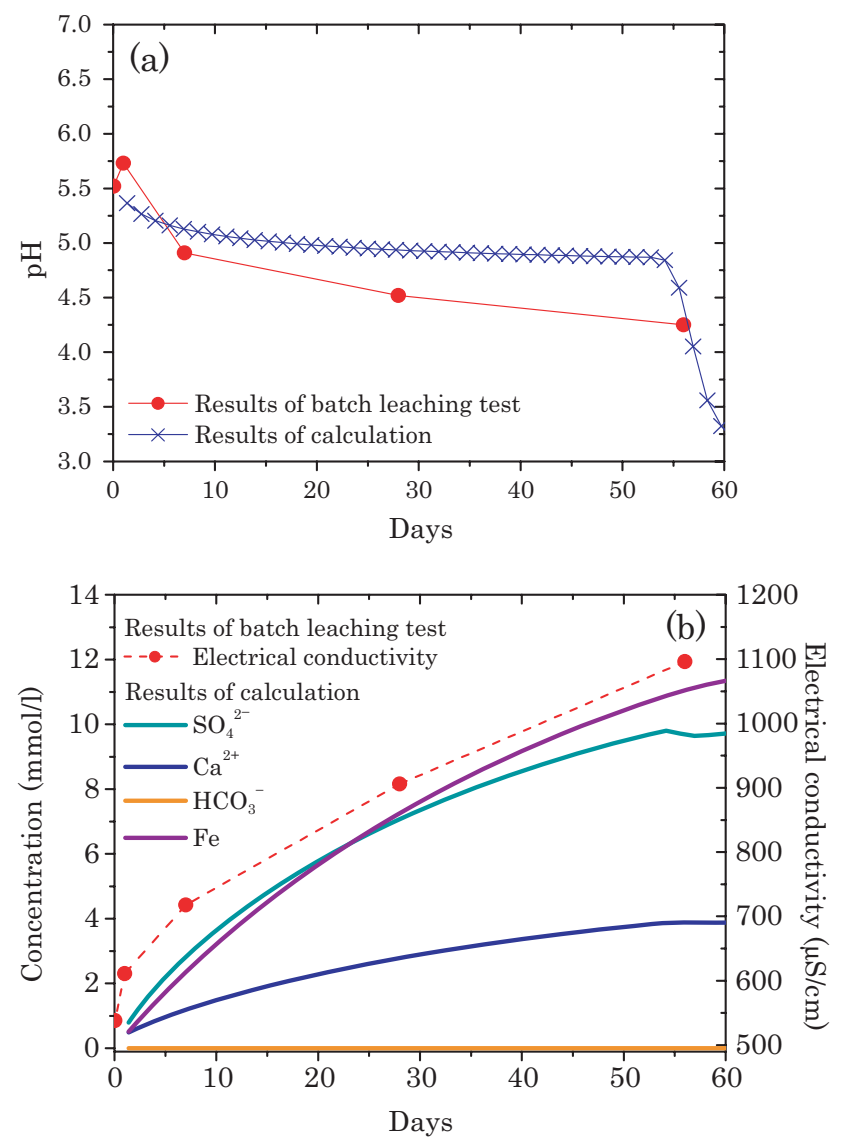

Fig. 8 Calculated water quality of the leachate in the numerical simulation against the results of the batch leaching test

\subsubsection{Simulation of the water quality changes in the column leaching test}

Simulation of the results of the column leaching test was attempted using PHREEQC with the same reaction models used in the simulation of the batch leaching test. The flow rate condition was also set to the flow rate of the leaching test. The calculated $\mathrm{pH}$ shows a value of lower than 5.0 until the 5-day point, after which it increases to 9.0 until 15 days later. Although the calculated $\mathrm{pH}$ values are different from the $\mathrm{pH}$ measured in the
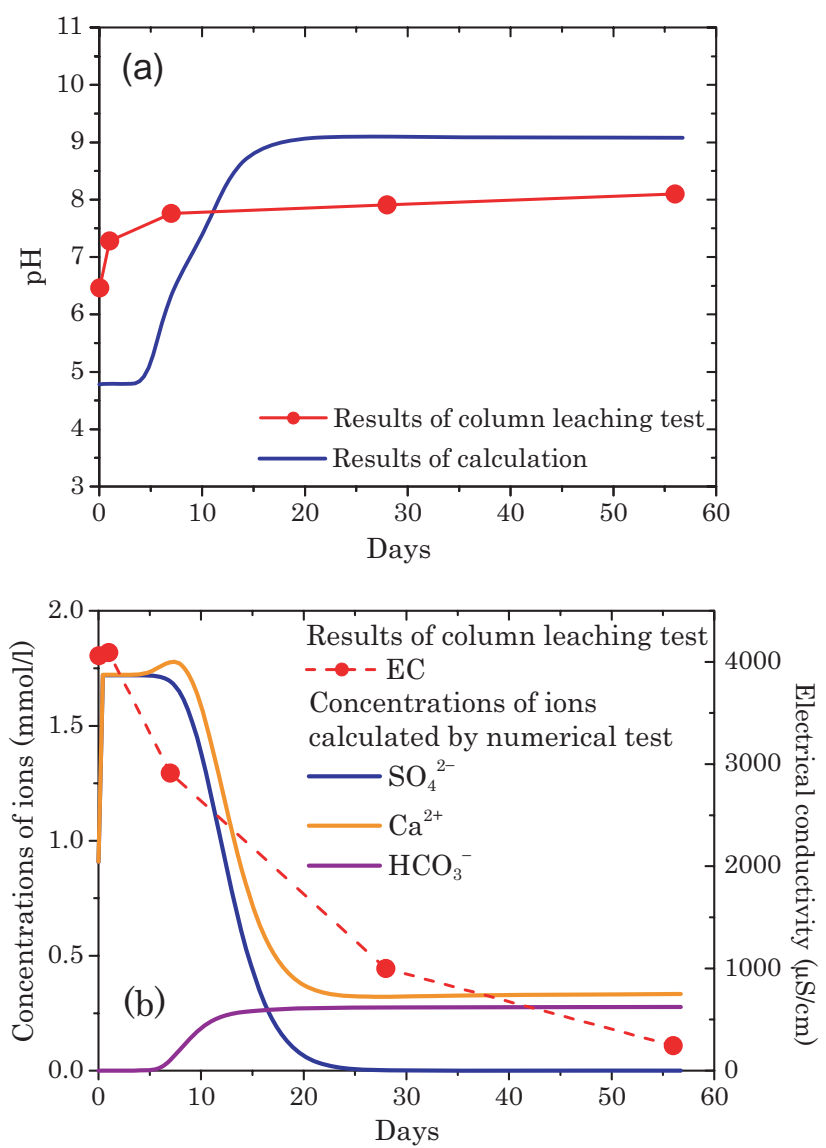

Fig. 9 Calculated water quality of the leachate in the numerical simulation against the results of the column leaching test

leaching test, the trend of change in the calculated $\mathrm{pH}$ is similar to that of the measured $\mathrm{pH}$ (Fig. 9a). The calculated calcium ion and sulfate concentration values increase immediately after 24 hours and then decrease until 25 days later (Fig. 9b). This trend is the same as the one for electrical conductivity changes in the leachate of the leaching test.

These results demonstrate the suitability of this numerical analysis to simulate the column leaching test. However, the precision of the simulation method such as input parameters needs to be improved.

\subsubsection{Water and mud sediment reaction mechanism in a kinetic state}

As described above, the changes in leachate water quality can be simulated using thermo-dynamic theory with reaction models assumed in a state of equilibrium. This result suggests that these models can be adopted as kinetic reaction models. We can therefore determine that the elements of the water and mud sediment reaction mechanism in a kinetic state are as follows:

1) Decomposition of pyrite

2) Decomposition of calcium-bearing minerals such as plagioclase and calcite

3) Water quality control caused by precipitation and/ or decomposition of gypsum 
4) Water quality control caused by precipitation of ferric hydroxide

\section{Study on the evaluation of environmental pollution based on numerical simulation}

To evaluate environmental pollution caused by acid water and heavy metal drainage from natural mud sediments, we must predict the discharge of these materials based on the assumed models and simulate the area of spread of the materials in the ground based on an advection/diffusion model. We simulated the diffusion of protons in the column leaching test using the computer program PHAST [4] to confirm the suitability of the advection/diffusion model for prediction of the polluted area. This program can simulate multi-component, reactive solute transport in a three-dimensional saturated groundwater flow system.

Figure 10 illustrates the calculated distribution of $\mathrm{pH}$ in a column at two days after the start of the test. In this calculation, the water and mud sediment reactions and the flow rate are modeled by the same (1) to (8) given in Chapter 2.3.2. As shown in this figure, the flow water input as distilled water becomes slightly alkaline at the output end of the column. This result agrees with the simulation results calculated using PHREEQC as shown in Fig. 9a. This indicates that analysis using PHAST can predict the pollution area in consideration of the groundwater flow.

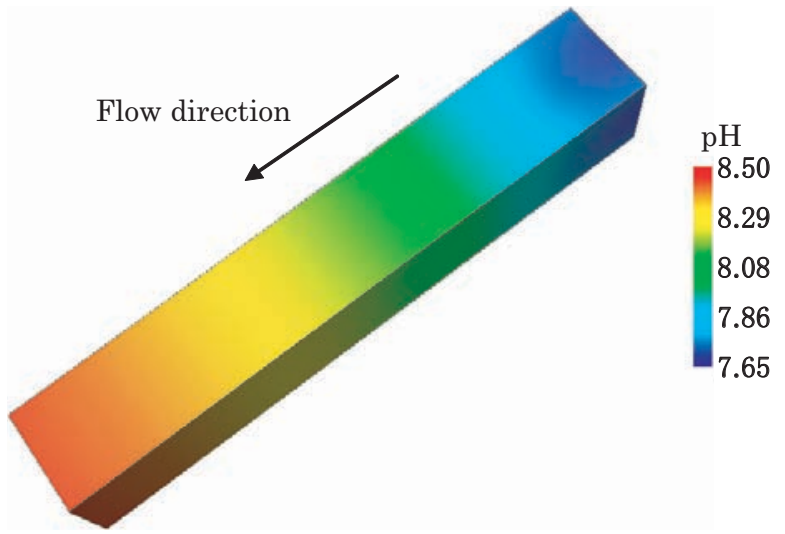

Fig. 10 Calculated distribution of $\mathrm{pH}$ in a column after 20 days

\section{Conclusions}

In order to evaluate the environmental pollution caused by acid water with heavy metals discharged from natural mud sediments, we investigated the water and mud sediment reaction mechanism through leaching tests and thermo-dynamic simulation. From the results of this investigation, the reaction mechanisms are assumed as follows: 1) pyrite decomposition, 2) calcium-bearing mineral decomposition, 3) precipitation and/or decomposition of gypsum, and 4) precipitation of ferric hydroxide. In addition, it is clear that the temporal and spatial distribution of $\mathrm{pH}$ in a column can be simulated by numerical analysis combined with thermo-dynamics theory and advection/diffusion theory based on the assumed reaction models.

These results indicate that it is possible to predict the spatial pollution caused by acid water and heavy metals discharged from natural ground using numerical analysis.

\section{Acknowledgment}

The authors would like to express their sincere gratitude to Prof. Tomochika Tokunaga for his guidance and teaching, without which the writing of this paper would not have been possible. The essential contribution of Dr. Hideo Kiya is also greatly appreciated.

\section{References}

[1] Stumm, W. and Morgan, J. J., Aquatic Chemistry, Chemical Equilibria and Rates in Natural Waters (3rd Edition), John Wiley \& Sons, Inc., New York, 1,022 p, 1996.

[2] The Japanese Geotechnical Society \& Kansai Geotechnical Consultants Association, The Ground of Osaka, Corona Publishing Co., Tokyo, 285p, 1987 (in Japanese).

[3] Parkhurst, D. L. and Appelo, C. A. J, User's Guide to PHREEQC (version 2) - A Computer Program for Speciation, Batch-Reaction, One-Dimensional Transport, and Inverse Geochemical Calculations, Water-Resources Investigations Report 99-4259, U.S. Geological Survey, $312 \mathrm{p}, 1999$.

[4] Parkhurst, D. L., Kipp, K. L., Engesgaard, P., Charlton, S. R. and Chang, J. K., PHAST-A Program for Simulating Ground-Water Flow, Solute Transport, and Multicomponent Geochemical Reactions, Techniques and Methods 6-A8, U.S. Geological Survey, 154p, 2004. 